\title{
Drinking water turbidity and gastrointestinal illness in the elderly of Philadelphia
}

\author{
Joel Schwartz, Ronnie Levin, Rebecca Goldstein
}

\begin{abstract}
Study objective-To investigate the association between drinking water quality and gastrointestinal illness in the elderly of Philadelphia.

Design-Within the general population, children and the elderly are at highest risk for gastrointestinal disease. This study investigates the potential association between daily fluctuations in drinking water turbidity and subsequent hospital admissions for gastrointestinal illness of elderly persons, controlling for time trends, seasonal patterns, and temperature using Poisson regression analysis.

Setting and participants-All residents of Philadelphia aged 65 and older in 19921993 were studied through their MEDICARE records.

Main results-For Philadelphia's population aged 65 and older, we found water quality 9 to 11 days before the visit was associated with hospital admissions for gastrointestinal illness, with an interquartile range increase in turbidity being associated with a $9 \%$ increase $(95 \%$ CI $5.3 \%$, $12.7 \%)$. In the Belmont service area, there was also an association evident at a lag of 4 to 6 days $(9.1 \%$ increase, $95 \%$ CI $5.2,13.3)$. Both associations were stronger in those over 75 than in the population aged 65-74. This association occurred in a filtered water supply in compliance with US standards.

Conclusions-Elderly residents of Philadelphia remain at risk of waterborne gastrointestinal illness under current water treatment practices. Hospitalisations represent a very small percentage of total morbidity.

(F Epidemiol Community Health 2000;54:45-51)
\end{abstract}

Epidemiology program, Harvard School of Public

Health, 665

Huntington Avenue,

Boston 02115, USA

J Schwartz

US Environmental

Protection Agency

R Levin

Department of

Biostatistics, Harvard

School of Public

Health

R Goldstein

Correspondence to:

Dr J Schwartz.

Accepted for publication 30 March 1999

It has long been known that drinking water contamination can be associated with epidemics of gastrointestinal (GI) disease. ${ }^{1}$ In response, three approaches were developed to avoid waterborne infectious diseases. Initially, emphasis was placed on developing a protected upland water source. In the early 1900s filtration and chemical disinfection with chlorine were introduced. Any one of these could reduce the mean death rate of typhoid from about 40-50 per 100000 (depending on the water source) to about 13 per 100000 , and two or more were thought to virtually eliminate waterborne infectious disease epidemics. ${ }^{2-4}$

Recently it has been shown that some of what is seen as "endemic" GI illness is actually waterborne. ${ }^{5-8}$ Children and the immunocom- promised population have been studied in particular $^{69}$ as has the general population. ${ }^{578}$ However, GI illness is a major health concern among the elderly, and the case-fatality rate for the elderly is higher than for other groups. ${ }^{10}$ The elderly are a growing segment of the population in most western countries.

This study examined the association between daily measures of drinking water turbidity and hospital admissions for GI illness of elderly residents of Philadelphia over the period 1992-1993, controlling for time trends, seasonality and temperature. Philadelphia has a generally well run, filtered and disinfected water system that consistently met EPA regulations throughout the study period. The source water is not protected, and comes from rivers passing through the city.

Drinking water turbidity, a measure of the cloudiness of the water, is commonly used as a proxy measure for the risk of microbial contamination and the effectiveness of the treatment of public drinking water. ${ }^{11}$ Several studies have shown a correlation between turbidity levels and microbial contamination of raw and treated water, ${ }^{12-14}$ and a few documented waterborne disease outbreaks were associated with increased turbidity levels ${ }^{15} 16$ although others reported no "increased" turbidity levels. ${ }^{9} 17$

The study design used here is a Poisson time series, comparing daily counts of hospital admissions with daily exposure measures (with lags to account for latency/incubation period). These methods have been widely used to evaluate the association between air pollution levels and hospital admissions for lung disease. ${ }^{18-24}$ The design is attractive because the population serves as its own control. Thus the only potential confounders are those that vary from day to day in correlation with exposure. EPA recently reviewed the corpus of such studies, and determined that methodologically, they are adequate to support EPA regulations. ${ }^{25}$

\section{Methods}

DATA

Environmental data

Three water treatment plants serve Philadelphia. The Belmont Plant receives its water from the Schuylkill River, which passes through the city of Philadelphia; Belmont treats about 60 million gallons of water per day (mgd) and serves much of the city west of the Schuylkill River. The Queen Lane Plant also gets its water from the Schuylkill River; it treats about $100 \mathrm{mgd}$ and serves the northwest portion of Philadelphia, until the Baxter service area. The Baxter Plant uses water from the 
Delaware River, which is Philadelphia's east border; it provides about $200 \mathrm{mgd}$ and serves the eastern part of the city. The Baxter Plant also supplements the Queen Lane Plant (NW Philadelphia) service area.

The Philadelphia Water Department (PWD) serves about 1.2 million people. All three treatment plants provide filtration, pre-chlorination and a chloramine residual, conventional water treatment (flocculation and sedimentation), and, as necessary, chemical corrosion inhibitors. PWD measures turbidity for compliance with EPA regulations that stipulate sampling frequency, methods, and analysis. PWD consistently met all federal regulations during the study period and there was no evidence of any operational disturbances.

PWD provided daily turbidity data for each plant for the two year period 1992-93 for each of the water treatment plants. No other water quality parameter was available to us on a daily basis. Turbidity measurements were made every three hours at each of the three water treatment plants. These were averaged for each day in each plant and that plant specific measure was used for the analysis of admissions for GI illness of persons residing in the service area of each plant. An overall city average was computed by taking the arithmetic mean of daily measurements from the three plants, weighting each plant by the proportion of elderly admissions coming from its service area. The primary analysis was by plant and citywide analysis was only considered when plant level analyses indicated similar results in each plant service area.

Daily temperature readings (24 hour mean) were obtained from Philadelphia International Airport, which is the nearest National Atmospheric and Oceanographic Administration weather station.

\section{Hospital visits}

All hospitals treating Medicare patients must submit standardised reports to the Health Care Financing Administration for each admission. From these reports we extracted the date of admission, zip code of residence, and the International Classification of Diseases, 9th revision (ICD-9) code for the discharge diagnosis for all residents with a zip code of residence in an area serviced by one of the three Philadelphia water treatment plants.

We restricted our study to ICD-9 codes plausibly related to GI illness. These include a primary diagnosis of GI related illness (ICD-9 codes 001 to 009.9 and 558.9) or associated general symptoms such as electrolyte disorders (ICD-9 276), nausea and vomiting (ICD-9 787), and abdominal pain (ICD-9 789). Symptom codes and the general "catch-all" 558.9 categories were included because there is evidence of coding biases, especially attributing a non-infectious origin to GI illnesses among the elderly, ${ }^{10}$ and because there is chronic under-reporting of waterborne illness, even for mortality in a well known to be at risk population following a massive and highly publicised waterborne disease outbreak. ${ }^{26}$ From these data we tabulated daily counts of hospital admissions for GI related illness for each day from 1 January 1992 to 31 December 1993, for persons aged 65 years and older. Because of the different sources of water for the plants, the counts of daily visits were computed separately for each plant service area. In addition, an overall daily count was computed.

\section{STUDY DESIGN}

The unit of analysis in this study is the day, so potential confounders that must be controlled are those that vary over time, possibly coincidentally with water quality. There are seasonal patterns in daily counts of hospital admissions that are independent of water quality. While weather variables may explain some of these patterns, it is unlikely to account for them all. The specific long wavelength pattern for GI illness probably varies from city to city, but generally shows a winter peak. ${ }^{10}{ }^{27}$

In this study, we regressed the daily counts of hospital admissions on turbidity levels, with control for seasonal variations and long term time trends, temperature, and day of the week effects. Separate analyses were done for each plant service area, and, if consistent patterns were seen, for the entire city.

Latencies for typical GI infections range from 1 to 14 days, ${ }^{28-30}$ so we considered turbidity levels between 1 and 14 days before the hospital visit in our analysis. Potential confounders in such a study design are limited to those that vary over time, such as seasonal patterns, temperature, and day of week effects.

Counts of daily admissions for GI illness are non-negative integers representing counts of rare events. Hence, Poisson regression analysis was used. To better control for potential non-linear dependencies on temperature, and for seasonal variation, we used the generalised additive model, ${ }^{31}$ which assumes that:

$\log [\mathrm{E}(\mathrm{Y})]=\beta 0+\mathrm{S}_{1}\left(\mathrm{X}_{1}\right)+\ldots+\mathrm{S}_{\mathrm{p}}\left(\mathrm{X}_{\mathrm{p}}\right)$

where $Y$ denotes the daily admission counts, $\mathrm{E}(\mathrm{Y})$ the expected daily counts, the $\mathrm{X}_{\mathrm{i}}$ are the covariates and the $S_{i}$ are smooth functions. The use of non-parametric smooth functions allows the dependence of hospital admissions on the covariates to be fit flexibly, as indicated by the data. The properties of such smoothers have been extensively discussed ${ }^{31}$ and used in environmental epidemiology. ${ }^{6} 72022$ We have used Loess, ${ }^{33}$ a moving regression smoother. All smooth functions require a smoothing parameter that describes how smooth the function should be. A smooth function of time was used to remove seasonal variation from the data, and the smoothing parameter was chosen to eliminate serial correlation in the residuals. The dependence of admissions on temperature involved two choices. Firstly, we had to choose the lag between temperature and hospital admission, and then we had to choose the smoothing parameter to use. We made both choices by minimising Akaike's Information Criteria, a goodness of fit criteria that trades off improvement in model fit with a penalty for using more degrees of freedom. Day of the week was controlled for using dummy variables for each day, and turbidity levels were entered into the regression model linearly to be 
Table 1 Distribution of daily environmental variables and daily hospital admissions for GI illness among the elderly of Philadelphia (1992-1993)

\begin{tabular}{|c|c|c|c|c|c|c|}
\hline & $10 \%$ & $25 \%$ & $50 \%$ & $75 \%$ & $90 \%$ & mean \\
\hline \multicolumn{7}{|l|}{ Hospital admissions } \\
\hline \multicolumn{7}{|l|}{ By age } \\
\hline $65-74$ & 0 & 1 & 2 & 4 & 5 & 2.4 \\
\hline $75+$ & 2 & 3 & 5 & 7 & 9 & 5.7 \\
\hline \multicolumn{7}{|l|}{ By plant } \\
\hline Belmont Plant & 0 & 1 & 1 & 2 & 3 & 1.6 \\
\hline Queen Lane Plant & 0 & 1 & 2 & 3 & 4 & 2.3 \\
\hline Baxter plant & 2 & 3 & 4 & 5 & 7 & 4.2 \\
\hline \multicolumn{7}{|l|}{ Environmental data } \\
\hline Temperature $\left({ }^{\circ} \mathrm{F}\right)$ & 34 & 42 & 55 & 71 & 78 & 56 \\
\hline \multicolumn{7}{|l|}{ Mean turbidity (ntu) } \\
\hline City & 0.14 & 0.16 & 0.19 & 0.21 & 0.23 & 0.19 \\
\hline Belmont Plant & 0.13 & 0.15 & 0.18 & 0.21 & 0.25 & 0.19 \\
\hline Queen Lane Plant & 0.14 & 0.16 & 0.20 & 0.24 & 0.27 & 0.20 \\
\hline Baxter Plant & 0.13 & 0.15 & 0.17 & 0.19 & 0.21 & 0.17 \\
\hline
\end{tabular}

conservative. The choice of lag between turbidity and hospital admission was chosen, like the temperature variable, to be the one that minimised Akaike's Information Criteria.

All analyses were conducted separately for the service area of each water treatment plant. If similarities in responses were seen across the plant service areas, the daily counts were combined and regressed against the weighted average turbidity levels to gain more power. If significant associations were found, we also examined whether age was a risk modifier for the association by separately regressing admission counts in the age ranges of $65-74$ and $\geqslant 75$.

\section{Results}

Table 1 shows the distribution of the hospital admissions and environmental data. There were a total of 6021 hospital admissions from
1 January 1992 to 31 December 1993; 19.6\% of patients resided in areas serviced by Belmont, 28.9\% serviced by Queen Lane and $51.5 \%$ serviced by Baxter. Turbidity levels were in general very low (mean $<0.20$ NTUs at all plants) and well below even the upcoming EPA standard.

In these data, the Pearson's correlation coefficient between temperature and the weighted average turbidity level was low, at 0.14 . The correlation between the seasonal pattern in GI hospital admissions and turbidity was similarly low, at -0.19 . Figure 1 shows the residuals from the regression of all elderly hospital admissions in the city, showing that the smooth function of time did eliminate seasonal patterns. Figure 2 shows the partial autocorrelation function of the same residuals. No significant serial correlation remained. Similar results were seen for the plant service area specific analyses.

Table 2 shows the results of the analyses. An association was found between turbidity levels with a lag of 9 to 11 days and hospital admissions for GI illness in all three water plant service areas. Because of the similarity in lags among the three plants, a citywide analysis was performed. The mean turbidity level between 9 and 11 days before admission was a better predictor of risk than any single day's lag (for example, day 10). An interquartile range increase in exposure (0.035 NTU) was associated with a $9 \%$ increase in admissions (95\% CI, 5.3, 12.7).

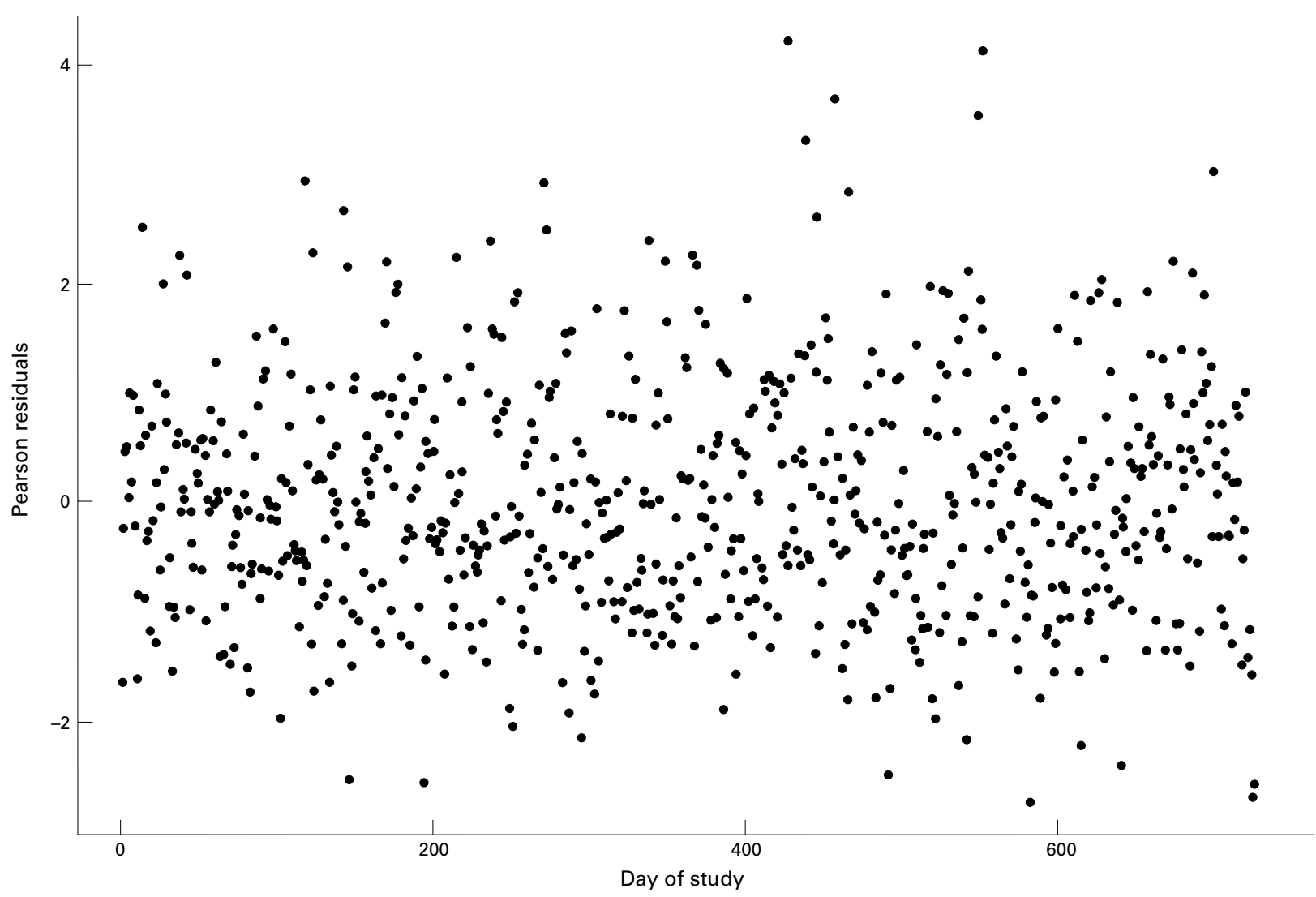

Figure 1 A plot is shown of the residuals from the regression of hospital admissions for gastrointestinal illness of all persons aged 65 and older in Philadelphia plotted against the day of admission. No seasonal pattern remains in the residuals, indicating the regression controlled adequately for season. 
Table 2 Per cent increase in hospital admissions for GI illness among the elderly of Philadelphia associated with an interquartile range increase in turbidity, 1992-1993

\begin{tabular}{llcl}
\hline & $\begin{array}{l}\text { Lag of } \\
\text { turbidity }\end{array}$ & $\begin{array}{l}\text { Per cent } \\
\text { increase }\end{array}$ & $\begin{array}{l}\text { 95\% } \\
\text { Confidence } \\
\text { intervals }\end{array}$ \\
\hline $\begin{array}{l}\text { Entire city } \\
\text { By water plant }\end{array}$ & 9-11 days & 9.0 & $(5.3,12.7)$ \\
$\quad$ Belmont plant & 4-6 days & 9.1 & $(5.2,13.3)$ \\
Queen Lane Plant & 11 days & 15.1 & $(7.8,12.3)$ \\
$\quad$ Baxter Plant & 9 days & 8.2 & $(0.6,16.4)$ \\
By age & 5.3 & $(0.4,10.4)$ \\
$\quad$ age 65-74 & 9-11 days & 2.5 & $(-3.8,9.1)$ \\
age 75+ & 9-11 days & 9.1 & $(5.2,13.3)$ \\
\hline
\end{tabular}

In addition to this common association with water quality about one and a half weeks earlier, in the Belmont area there was also an association with the average turbidity 4 to 6 days before admission $(9.1 \%$ increase for an interquartile range increase in turbidity, 95\% CI 5.2, 13.3). The three day average (days 4-5-6) was a better predictor than turbidity five days earlier.

When the data were stratified by age, the association with turbidity 9 to 11 days before admissions was strongest in those $>75(10.8 \%$ $v 2.5 \%$, table 2). Again, in the Belmont area, the lag of 4 to 6 days was primarily in the eldery - that is, those 75 and over.

To assure that the association between turbidity and GI hospital admissions was not a chance result of one positive association among 14 lags being considered, we examined the sign of the association at all other lags in all three plant service areas. Out of the 42 possible associations (14 in each service area), only seven were negative. The probability of this occurring given the null hypothesis is less than 0.0001 .

\section{Discussion}

In this study, we found an association between turbidity levels and hospital admissions for GI illness within the elderly population in Philadelphia over the period 1992-1993. In all three water treatment plant service areas, turbidity levels lagged 9 to 11 days were associated with hospital admissions (9\% increase for an interquartile range increase in exposure). Residents of the Belmont service area also showed an increased risk (9.1\% increase) 4 to 6 days after exposure.

These findings are quite similar to those previously reported for paediatric emergency visits for GI illness in Philadelphia. ${ }^{6}$ That study reported emergency visits associated with turbidity lagged 10 days in the Belmont and Queen Lane service areas, and lagged nine days in the Baxter service area. Combining all service areas, an association was seen with a 10 day lag. In addition, an association in the Belmont service area with a four day lag was seen.

Overall, in this analysis the strongest association between drinking water quality and hospitalisations for GI illnesses in Philadelphia's elderly occurred in people 75 years old and older.

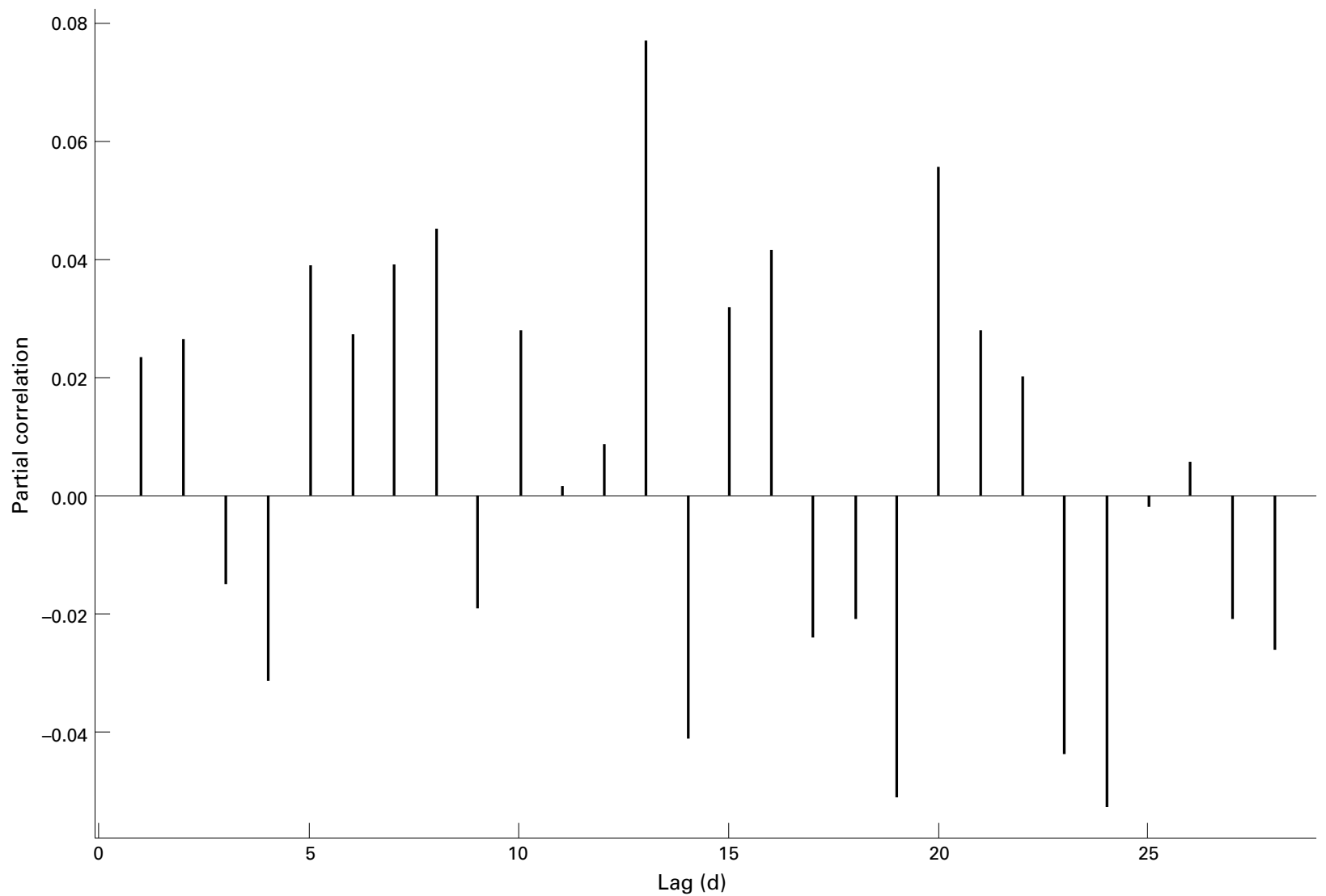

Figure 2 This shows the partial autocorrelation function of the residuals of the regression of hospital admissions for gastrointestinal illness of all persons aged 65 and older in Philadelphia. There is no significant correlation at any lag, indicating that serial correlation in residuals is not a problem in the analysis. 
The lags observed are plausible for waterborne GI disease. Estimates of the actual incidence of waterborne disease suggest that the most common waterborne GI illnesses are viral and protozoan. ${ }^{34}{ }^{35}$ Incubation periods for these generally range from two days to two weeks. ${ }^{28-30}$

This study and similar ones ${ }^{5-9}$ show a significant level of GI disease, including hospitalisations, associated with consumption of drinking water in the US and Canada, even in well run, state of the art water systems with no evidence of operation disruptions. The generally very low turbidity levels in Philadelphia would meet EPA's upcoming Interim Enhanced Surface Water Treatment Rule. The costs of this morbidity are also likely to be significant; average hospital costs are now over $\$ 1000 /$ day. Hospitalisations, of course, represent only a small percentage of total associated morbidity.

POTENTIAL BIASES AND LIMITATIONS OF THE

DATA

Turbidity is a measure of the presence of suspended particles in water that are capable of scattering light. Microorganisms are only a tiny portion of these particles (most is mud and silt), and pathogenic microbes are likely to be only a tiny fraction of the total microbial population. Turbidity, then, is a proxy for exposure. In the case of the Philadelphia water supply, the source water is highly contaminated, but it is treated and filtered. Hence, here turbidity may serve as a proxy for the ability of filtration to remove contaminants, including pathogens. ${ }^{11}$ This relation probably varies day to day, introducing error into our exposure estimate.

There is also measurement error associated with the turbidity measures. Firstly, there were reporting differences among Philadelphia's three water treatment plants. In addition, one study of variability in low level turbidity measurements found a wide but normally distributed variability; the instruments and calibration standard, which were the same in Philadelphia's three water plants, were the principal factors related to variability in that study. ${ }^{36}$ Random measurement error will decrease the estimated risk because, in a regression analysis, the variability in the independent variable is compared with the variability in the dependent variable. Fortunately, the large size of the data base in this study, especially the fact that each day's turbidity was the average of 24 measurements, increases overall accuracy.

Additional measurement error comes from the exposure links-date of exposure and zip code of residence. "Date" is imprecise because the transit time in the distribution systemthat is, the time from water treatment plant to home tap-varies irregularly throughout the city. The date of exposure we used was the date the water left the treatment plant. Assignment of people to treatment plant by zip code is imprecise because people consume water from faucets other than their own residences, both within and outside the city. In addition, many parts of Philadelphia receive water that is blended from two or more of the water treatment plants.
KEY POINTS

- Disinfected drinking water in Western countries may still be a source of infectious gastrointestinal illness.

- Some of what is now considered endemic illness may be waterborne.

- Because of the large number of waterborne pathogens biological monitoring is rare, and proxies for contamination are used. Better proxies should be developed, and supplemented with routine monitoring of gastrointestinal illness.

In a univariate regression, misclassification of exposure biases effect estimates to the null. In multivariate regression, the effects are more complicated. However, the probability limit of the bias in the regression coefficient of the exposure of interest can be separated into two terms. One only involves the measurement error for the exposure variable, and again biases toward the null. The second term is proportional to the measurement error of the other covariates, and their correlation with exposure. This term can bias in either direction, depending on the signs of the correlations. ${ }^{37}$ In this analysis, the exposure misclassification is relatively high and the correlation between turbidity and the covariates (season, day of week, and temperature) is moderately low. The net bias in the estimated effect of microbial contamination of drinking water, then, is likely to be toward an underestimate of effect.

Misclassification of disease is less intractable. The accuracy of discharge diagnoses were $90 \%$ when closely related diagnostic categories, such as the GI categories used here, were grouped. ${ }^{38}$ Furthermore, little evidence was seen for systematic missclassification of diagnoses into more financially rewarding diagnoses, ${ }^{39}$ and diagnostic accuracy was higher in large cities, and in later years. ${ }^{40}$

Random misclassification of the outcome variable in regression will not bias the estimated attributable risk for exposure, it will only increase the standard error of the estimated risks. ${ }^{41}$ To see this consider first a linear model for the response variable

$$
\mathrm{Y}=\mathrm{X} \beta
$$

Where $\mathrm{X}$ is a matrix of predictor variables, $\beta$ a vector of regression coefficients, and $Y$ the vector of daily counts. Suppose instead of Y, we measure $\mathrm{Z}$ on each day, where $\mathrm{Z}$ is the count of GI admissions including net missclassification. Then, using the usual formula for the estimated regression coefficients, we find that $\beta=\left(\mathrm{X}^{\mathrm{t}} \mathrm{X}\right)^{-1} \mathrm{X}^{\mathrm{t}} \mathrm{Z}=\left(\mathrm{X}^{\mathrm{t}} \mathrm{X}\right)^{-1} \mathrm{X}^{\mathrm{t}} \mathrm{Y}+\left(\mathrm{X}^{\mathrm{t}} \mathrm{X}\right)^{-1} \mathrm{X}^{\mathrm{t}} \mathrm{e}$

Where $\mathrm{X}^{\mathrm{t}}$ is the transpose of the $\mathrm{X}$ matrix, and $\mathrm{e}$ is $\mathrm{Z}-\mathrm{Y}$, the missclassification error. As up to normalisation $\mathrm{X}^{\mathrm{t}} \mathrm{e}$ is the correlation between the exposure variables and the misdiagnosis error from day to day, we see that unless the net misdiagnosis on a daily basis was correlated with turbidity, there is no bias in the regression coefficient. In our case, we have fit a log-linear model

$\mathrm{Y}=\exp (\mathrm{X} \beta)$ 
But for small relative risks, which is what we see in this study, we can $\operatorname{expand} \exp (\mathrm{X} \beta)$ as a power series and keep only the first term, recovering the situation above. Hence, such misclassification reduced the significance of the coefficients, but should not have biased the effect estimate.

This discussion assumes that these diagnosis errors are not correlated with exposure. While it is possible that there is a time trend of misclassification that might be correlated with a long term time trend in exposure, such long term time trends are filtered out in this analysis by the Loess smooth function of time. We cannot identify a likely scenario by which diagnostic patterns would change day to day in correlation with turbidity measurements.

DRINKING WATER AND GI DISEASE IN THE UNITED STATES

Several recent studies have indicated that, even in systems meeting current federal and state standards, some of what has been understood an endemic GI illness in the US is actually waterborne infectious disease. All the systems studied met then current federal water standards and, with the exception of a very brief period during a massive outbreak of cryptosporidiosis in Milwaukee, all would meet current federal drinking water standards. Those studies have focused on the general population, children, and immunocompromised people. This analysis extends those findings to another sensitive group - the elderly.

Several studies have shown that GI illness is a "special burden" of the elderly. Hospitalisation and case-fatality rates for GI illness in the elderly are disproportionately high. ${ }^{1027} \mathrm{Com}-$ munity surveys have confirmed that acute gastroenteritis is a common disease in nursing homes, ${ }^{42}$ including a study conducted in the Philadelphia $\operatorname{area}^{43}$; and in the noninstitutionalised elderly population in Europe as well as in the US. ${ }^{44} \mathrm{~A}$ recent survey of the published literature to identify populations particularly sensitive to waterborne and foodborne enteric microorganisms found that they included the very young, the immunocompromised and the elderly. ${ }^{45}$

The legion of elderly is growing rapidly. The number of persons over 65 is estimated to double between 1980 and 2010, from about 25 to 50 million. And the number of people over 85 will likely triple in that time, from about 2.2 million to 7.5 million.

Thus, GI disease, both morbidity and mortality, has significant social and economic costs in the US, especially among the elderly. Given the slow aging of the entire US population and the disproportionate burden of GI disease in the elderly population, these costs can be expected to rise.

We thank the Philadelphia Water Department for providing the turbidity data.

This paper represents the views of the authors and does not represent the views of the US Environmental Protection Agency. Funding: this study was supported by grant ES-0002 of the
National Institute for Environmental Health Sciences. Conflicts of interest: none.
1 Snow J. On the mode of communication of cholera. London: Churchill, 1855.

2 Kober GM. Conservation of life and health by improved water supply. Engineering Record 1908;57.

3 Water Works Practice Manual. Denver, CO: American Water Works Association, 1925.

4 Okun DA. From cholera to cancer to crytosporidiosis. fournal of Environmental Engineering 1996;122:453-58.

5 Payment P, Richardson L, Siemiatycki J, et al. A randomized trial to evaluate the risk of gastrointestinal disease due to consumption of drinking water meeting current microbiological standards. Am f Public Health 1991;81:703-8.

6 Schwartz J, Levin R, Hodge K. Drinking water turbidity and pediatric hospital use for gastrointestinal illness in Philadelphia. Epidemiology 1997;8:615-20.

7 Morris RD, Naumova EN, Levin R, et al. Temporal Morris $\mathrm{RD}$, Naumova $\mathrm{EN}$, Levin R, et al. Temporal
variation in drinking water turbidity and diagnosed variation in drinking water turbidity and diagnosed
gastroenteritis in Milwaukee. Am 7 Public Health 1996;86: 237-9.

8 Payment P, Siemiatycki J, Richardson L, et al. A prospective epidemiological study of gastrointestinal health effects due to the consumption of drinking water. International fournal of Environmental Health 1997;7:5-31.

9 Goldstein ST, Juranek DD, Ravenholt O, et al. Cryptosporidiosis: An outbreak associated with drinking water despite state-of-the-art water treatment. Ann Intern Med 1996;124:459-68.

10 Gangarosa RE, Glass RI, Lew JF, Boring JR. Hospitalizations involving gastroenteritis in the United States, 1985: The special burden of the disease among the elderly. $A m \mathcal{F}$ Epidemiol 1992;135:281-90.

11 EPA. Drinking water criteria document for turbidity. Washington, DC: Drinking Water Research Division, Office of ton, DC: Drinking Water Research

12 LeChevallier MW, Norton WD. Treatments to address source water concerns: Protozoa. In: Craun G, ed. Safety of source water concerns: Protozoa. In: Craun G, ed. Safety of water disinfection: balancing chemical and mic

13 Clark SC, Lawler DF, Cushing RS. Contact filtration: particle size and ripening. Fournal of the American Water Works Association 1992;84:61-71.

14 LeChevallier MW, Norton WD, Lee RD. Occurrence of Giardia and Cryptosporidium in surface water supplies. $A p p l$ Environ Microbiol 1991;57:2610-16.

15 MacKenzie WR, Hoxie NJ, Proctor ME, et al. A massive outbreak in Milwaukee of Cryptosporidium infection transmitted through the public water supply. $N$ Engl F Med 1994;331:161-7.

16 Kent JP, Greenspan JR, Herndon JL, et al. Epidemic giardiasis caused by a contaminated public water supply. giardiasis caused by a contaminated

17 Hayes EB, Matte TD, O'Brien TR, et al. Large community outbreak of crypotosporidiosis due to contamination of a filtered public water supply. $N$ Engl f Med 1989;320: $1372-6$

18 Bates DV, Sizto R. Air pollution and hospital admissions in Southern Ontario: the acid summer haze effect. Environ Res 1987;43:317-31.

19 Schwartz J. Air pollution and hospital admissions for the elderly in Birmingham, Alabama. Am f Epidemiol 1994; 139:589-98.

20 Anderson HR, Spix C, Medina S, et al. Air pollution and daily admissions for chronic obstructive pulmonary disease in 6 European cities: results from the APHEA project. Eur Respir f 1997;10:1064-71.

21 Schwartz J. Short term fluctuations in air pollution and hospital admissions of the elderly for respiratory disease. Tho$\operatorname{rax}$ 1995;50:531-8.

22 Ponce de Leon A, Anderson HR, Bland JM, et al. Effect of air pollution on daily hospital admissions for respiratory disease in London between 1987-88 and 1991-92. F Epidemiol Community Health 1996;50 (suppl 1):S63-70.

23 Thurston GD, Ito K, Kinney PL, et al. A multi-year study of air pollution and respiratory hospital admissions in three New York State metropolitan areas: results for 1988 and 1989 summers. F Expo Anal Environ Epidemiol 1992;2:42950.

24 Burnett R, Dales RE, Raizenne ME, et al. Effect of low ambient levels of ozone and sulphates on the frequency of respiratory admissions to Ontario hospitals. Environ Res 1994;65:172-94.

25 EPA. Air quality criteria for particulate matter. Washington, DC: Office of Research and Development, 1996. EPA/600/ DC: Office of

26 Hoxie NJ, Davis JP, Vergeront JM, et al. Cryptosporidiosisassociated mortality following a massive waterborne outbreak in Milwaukee, Wisconsin. Am F Public Health 1997;87:2032-5.

27 Lew JF, Glass RI, Gangarosa RE, et al. Diarrheal deaths in the United States, 1979 through 1987: a special problem for the elderly. $\mathscr{F A M A} 1991 ; 265: 3280-4$.

28 Dolan R. Norwalk and related agents of gastroenteritis. In: Mandell GL, Douglas RG, Bennett JE, eds. Principles and practice of infectious diseases. New York: John Wiley, 1985:995-1000.

29 Hill DR. Giardia lamblia. In: Mandell GL, Douglas RG, Bennett JE, eds. Principles and practice of infectious diseases. New York: John Wiley, 1985:1552-6.

30 Guerrant RJ, Hughes JM. Nausea, vomiting and noninflammatory diarrhea. In: Mandell GL, Douglas RG, Bennett $\mathrm{JE}$, eds. Principles and practice of infectious diseases. New York: John Wiley, 1985:646-55. 
31 Hastie T, Tibshirani R. Generalized additive models. London: Chapman and Hall, 1990.

32 Kelsall JE, Samet JM, Zeger SL, et al. Air pollution and mortality in Philadelphia, 1974-1988. Am f Epidemiol 1997;146:750-62.

33 Cleveland WS, Devlin SJ. Robust Locally-weighted regression and smoothing scatterplots. Fournal of the American Statistical Association 1988;74:829-36.

34 Bennet JV, Holmberg SD, Rogers MF, et al. Infectious and parasitic diseases. In: Amler RW, Dull HB, eds. Closing the gap: the burden of unnecessary illness. New York: Oxford University Press, 1987:102-14.

35 Morris RD, Levin R. Estimating the incidence of waterborne infectious disease related to drinking water in the United States. In: Reichard EG, Zapponi GA, eds. Assessing and managing health risks from drinking water contamination. Great Britain: IAHS Press (International Association Hydrological Sciences), 1985:75-88.

36 Hart VS, Johnson CE, Lederman RD. An analysis of low-level turbidity measurements. Fournal of the American Water Works Association 1992;84:40-5.

37 Judge GG, Griffiths WE, Carter Hill R, et al. The theory and practice of econometrics. New York: John Wiley, 1985.
38 Delfino R, Becklake MR, Hanley JA. Reliability of hospital data for population-based studies of air pollution. Arch Environ Health 1993;48:140-6.

39 Hsia DC, Krushat WM, Fagan AB, et al. Accuracy of diagnostic coding for Medicare Patients under the prospectivepayment system. N Engl F Med 1988;318:352-5.

40 Hsia DC, Ahern CA, Ritchie BP, et al. Medicare reimbursement accuracy under the prospective payment system, 1985-1988. ҰAMA 1992;268:896-9.

41 Schwartz J. Air pollution and hospital admissions for the elderly in Minneapolis. Arch Environ Health 1994;49:366-74.

42 Garibaldi RA, Brodine S, Matsumiya S. Infections among patients in nursing homes: policies, prevalence and problems. N Engl f Med 1981;305:731-5.

43 Sims RV, Hauser RJ, Adewale AO, et al. Acute gastroenteritis in three community-based nursing homes. 7 Gerontol 1995;50:M252-6.

44 Jeandel C, Laurain MC, Decottignies F. Infectious diarrhea in the aged. Revue du Praticien 1996;46:184-8.

45 Baert D, DeMan M, Oosterbosch L, et al. Infectious gastroenteritis: are they all the same? Acta Clin Belg gastroenteritis: are 